\title{
Ophthalmic atropine for sublingual use: A novel treatment for excessive respiratory secretions
}

\author{
Paul Staffieri ${ }^{1}$, Kent A. Owusu*2, Maria Cardinale ${ }^{3}$, Amber Castle $^{2}$ \\ ${ }^{1}$ University of Illinois at Chicago College of Pharmacy, Illinois, USA \\ ${ }^{2}$ Department of Pharmacy, Yale-New Haven Hospital, New Haven, CT, USA \\ ${ }^{3}$ Ernest Mario School of Pharmacy, Rutgers, The State University of New Jersey, Piscataway, NJ, USA
}

Received: June 10, 2016

DOI: $10.5430 /$ crim.v3n3p 82
Accepted: June 30, $2016 \quad$ Online Published: July 24, 2016

URL: http://dx.doi.org/10.5430/crim.v3n3p82

\begin{abstract}
We describe a novel case of utilizing ophthalmic atropine suspension via sublingual route to control excessive secretions in a critically ill patient. In addition, a medication event related to a labeling and administration event is described where the patient received the drug via ophthalmic route. A 32-year-old Hispanic female presenting with NMDA-receptor antibody mediated encephalitis experienced a prolonged intensive care unit (ICU) stay secondary to hypercarbic respiratory failure complicated by excessive respiratory secretions. After one week on mechanical ventilation, the patient was set to undergo a percutaneous endoscopic gastrostomy (PEG) tube placement and tracheotomy. The patient's respiratory status was compromised by copious secretion production, preventing the patient from being transitioned to the general care floor. For secretion control, pharmacological interventions such as scopolamine transdermal patches and glycopyrrolate oral tablets were trialed, however systemic exposure to these agents resulted in urinary retention requiring catherization with a mild and persistent tachycardia. Ophthalmic atropine was administered sublingually at a dose of $1 \mathrm{mg}$ every six hours to provide local relief of the patient's secretion production. Secretion production improved within 72 hours and the patient's urinary retention resolved at the time of scopolamine and glycopyrrolate discontinuation. Previously in the literature the use of sublingual atropine was only described for secretion control in patients receiving end of life care, drug induced sialorrhea and neuro-developmental disorders. As observed in this case report, sublingual atropine may be an effective treatment to control respiratory secretions in critically ill patients who are unable to tolerate other therapies.
\end{abstract}

Key Words: Sublingual atropine, Critical care, Respiratory secretions, Anticholinergic, Sialorrhea

\section{INTRODUCTION}

Excessive respiratory secretions can compromise respiratory drive, increase the risk of aspiration, and may require either chronic or short-term respiratory support. ${ }^{[1]}$ Patients requiring ventilatory support can be found in all health-care settings including the community, long-term care, hospice and acute care. Conditions that may exacerbate secretion production include infection, poor respiratory drive and de- hydration. Patients who are receiving end of life (EOL) care may experience what is referred to as a "death rattle", a distressing respiratory event caused by excessive respiratory secretions. ${ }^{[2]}$ This can be extremely distressing for both patients and their families. Optimizing respiratory secretion control may improve patient comfort and compliance with mechanical ventilation.

*Correspondence: Kent A. Owusu; Email: Kent.Owusu@YNHH.ORG; Address: Department of Pharmacy, Yale-New Haven Hospital, 20 York Street, New Haven, CT 06510, USA. 
The most readily available pharmacological pathway avail- vary glands resulting in decreased saliva production. ${ }^{[6]}$ Atable to reduce secretion production is the anticholinergic pathway. Scopolamine patches, glycopyrrolate, and hyoscyamine can be used for their anticholinergic properties to reduce secretions. However, these medications have systemic effects including tachycardia, urinary retention, constipation and blurred vision. Since these medications may pass the blood-brain-barrier, they can also cause fluctuations in mental status. ${ }^{[2,3]}$

Atropine is a naturally occurring metabolite of alkaloid compounds extracted from deadly nightshade (atropa belladona). Atropine's anticholinergic properties were first discovered when it was used as a cosmetic to dilate pupils. ${ }^{[4]}$ As a parasympatholytic, it is a competitive antagonist for multiple muscarinic receptors. ${ }^{[4,5]}$ As an anti-secretagogue, atropine has a high affinity for muscarinic-3 (M3) receptors, on sali-

ropine is available in both intravenous and ophthalmic dosage forms. When administered parenterally atropine may exhibit systemic anticholinergic effects such as tachycardia, hypohydrosis, and altered mental status. ${ }^{[7]}$ However, sublingual administration of the opthalmic solution may be advantageous by minimizing adverse systemic exposure. ${ }^{[2-5]}$ The off-label use of atropine for secretion control has been well studied in palliative care and has been reportedly used in patients with neurodevelopmental disorders and antipsychotic induced sialorrhea. ${ }^{[2,5,6]}$ Outside of these indications, there is limited evidence to support its use in more general patient populations. $^{[2,5,6,8]}$ Table 1 summarizes published evidence examining the use of sublingual atropine outside the scope of palliative care. To our knowledge, this is the first case report of a patient treated with sublingual atropine outside of the aforementioned indications.

Table 1. Evidence supporting sublingual atropine outside of palliative care

\begin{tabular}{|c|c|c|c|c|c|}
\hline Study & Design & Patient population & Atropine product & Dosing & Findings \\
\hline Mustafa et al. ${ }^{[5]}$ & Case report & $\begin{array}{l}\text { Clozapine induced } \\
\text { sialorrhea }\end{array}$ & $1 \%$ ophthalmic solution & $\begin{array}{l}0.5 \mathrm{mg} \text { (one drop) three } \\
\text { times daily as needed }\end{array}$ & $\begin{array}{l}\text { Suctioning frequency decreased. } \\
\text { No adverse events reported }\end{array}$ \\
\hline Rapoport A. ${ }^{[6]}$ & Case report & $\begin{array}{l}\text { Pediatric } \\
\text { neurodevelopment disorder }\end{array}$ & $0.5 \%$ ophthalmic solution & $\begin{array}{l}0.25 \mathrm{mg} \text { (one drop) every } \\
\text { six hours as needed }\end{array}$ & $\begin{array}{l}\text { Benefit within } 24 \text { hours of starting. } \\
\text { Suctioning events decreased to } 1-2 \text { times daily. } \\
\text { Dystonia after } 2 \text { weeks of administration }\end{array}$ \\
\hline $\begin{array}{l}\text { Hyson CH, Johnson } \\
\text { AM, Jog MS. }{ }^{[10]}\end{array}$ & $\begin{array}{l}\text { Open-label } \\
\text { pilot }\end{array}$ & Parkinsonism & $1 \%$ ophthalmic solution & $\begin{array}{l}0.5 \mathrm{mg} \text { (one drop) twice } \\
\text { daily }\end{array}$ & $\begin{array}{l}\text { Reduction in sialorrhea at } 180 \text { minutes. } \\
\text { Benefit sustained up to } 1 \text { week. } \\
\text { Questionable adverse events related to } \\
\text { pre-existing conditions }\end{array}$ \\
\hline
\end{tabular}

\section{Case presentation}

A 32-year-old Hispanic female with past medical history significant only for hysterectomy secondary to ovarian cysts one year prior to admission presented with a newly diagnosed NMDA-receptor antibody mediated encephalitis. On presentation, she had altered mental status requiring mechanical ventilation as she could not protect her airway. After one week of mechanical ventilation the patient underwent both percutaneous endoscopic gastrostomy (PEG) tube and tracheotomy. The patient tolerated both procedures well but subsequently developed excessive respiratory/oral secretions not related to infectious or other iatrogenic sources, ultimately preventing transfer to a lower level of care.

Prior to pharmacological intervention, the patient produced copious amounts of sputum requiring hourly suctioning. Initial pharmacological intervention included scopolamine 0.3 mg transdermal patch, which after a two-week trial had minimal impact on secretion control. The patient's urine output decreased (measured via urinary foley catheter) and she developed a mild persistent tachycardia (resting heart rate 110 beats per minute) possibly as a result of systemic exposure to scopolamine. Glycopyrrolate $1 \mathrm{mg}$ tablets were initiated after scopolamine failed to produce benefit. Glycopyrollate tablets were administered via the patient's PEG tube every eight hours. This intervention provided a modest benefit in secretion control as observed as a reduction in suctioning frequency from hourly to every two hours. However, symptoms of urinary retention requiring catherization and tachycardia persisted likely secondary to side effects associated with glycopyrollate tablets.

At this point, the medical team initiated one drop of atropine $1 \%$ ophthalmic solution sublingually every six hours. Commercially available atropine labeled for ophthalmic use was dispensed in the original packaging with administration instructions directing nurse to administer via sublingual route. Prior to administration, the patient required suctioning every two hours. Sputum production reduced per nursing documentation, and the patient's suctioning requirements decreased to once every four hours as needed within 72 hours of initiating atropine therapy, allowing glycopyrrolate to be discontinued. Within two weeks of sublingual atropine initiation, the team was able to discontinue scopolamine therapy. Two weeks after initiating sublingual atropine therapy, urine output improved allowing for removal of urinary foley catheter. The 
patient returned to her baseline voidance of five-six times daily via straight urethral catheterization. Resting heart rate also decreased to approximately 90 beats per minute.

During the next two months, the patient received atropine drops sublingually as monotherapy. There were no reports of systemic anticholinergic side effects, and secretion control vastly improved. Approximately 30 days after atropine was initiated, the patient experienced a medication event. Despite administration instructions provided via labeling to administer via sublingual route, atropine was inadvertently administered via ophthalmic route, resulting in a pronounced mydriasis. The patient subsequently received an emergent neurological work up including a computerized tomography (CT) scan of the head which was negative for an acute intracranial process.

Atropine was continued for another two weeks before discontinuation. Over time her cough, secretions, and pulmonary clearance improved, which were positive indicators of improved pulmonary function. Her tracheotomy was eventually decannulated and after a lengthy six month admission the patient was discharged home.

\section{Discussion}

This case describes the use of sublingual atropine for a patient with an acute neurologic illness and excessive respiratory secretions who was not terminally ill. Similarly to the described literature, our patient experienced a benefit in secretion control within 72 hours, and adverse events were not present. Mustafa et al. described the use of sublingual atropine in a patient with clozapine induced sialorrhea refractory to optimized hyoscine hydrobromide therapy. Sialorrhea did not recur even after discontinuation of sublingual atropine once symptoms resolved. ${ }^{[5]}$ As reported previously, the local administration of atropine exhibited a rapid reduction in secretion production. Although the other cases may have had confounding sources of sialorrhea (i.e. clozapine induced), the overall effect was consistent. An obvious limitation of this evidence is the small sample size and lack of prospective controlled trials. The majority of existing literature regarding the use of sublingual atropine resides in the field of palliative care, which has different goals of treatment than in the critically ill.

Although the patient did experience a clinical benefit while on this therapy, she also experienced a medication administration error. It is important to note that administration via any route than the labeled route is inherently error-prone. The provider administering the atropine was unfamiliar with its sublingual administration route. At our institution during the time of this case, when atropine was to be administered sublingually, the entire bottle (commercially labeled "for ophthalmic use only") was dispensed to the patient care area with directions for sublingual administration. It is important to note that at this time, our institution's computerized physician order entry system (CPOE) did not have an option to select "sublingual" as a route of administration for atropine. Manual entry of "for sublingual use only" into the administration instructions section was required. However, the route in the CPOE remained as the ophthalmic route. Atropine was dispensed in the original container but with highlighted notes indicating the appropriate route of administration on all sides of the container. We recognized that this was a risk point and took measures at that time to prevent inadvertent administration via the ophthalmic route. The prescriber, nurse and pharmacist were all communicated with, but after several days there was a gap in handoff which is when we identified the error. To prevent future errors regarding sublingual administration of ophthalmic atropine, it was recognized that a safer process was needed.

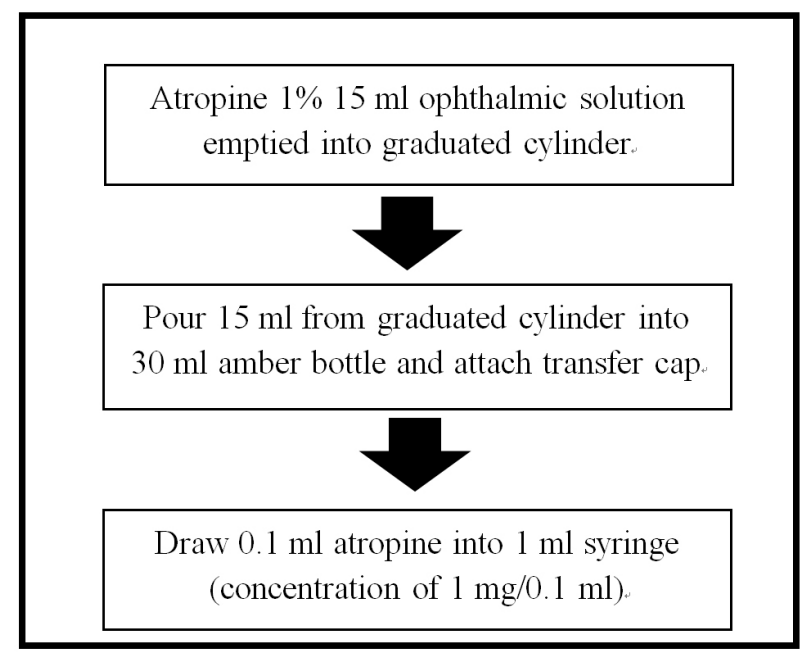

Figure 1. Unit dose repackaging of ophthalmic atropine for sublingual administration

First, to improve CPOE order process, a route of administration for sublingual use was built into the ordering screen. To minimize errors associated with misinterpretation of the intended route of administration as well as atropine dosing, we utilized a repackaging strategy to differentiate the ophthalmic container from a sublingual container (oral syringe). Figure 1 demonstrates the process of repackaging the ophthalmic solution into unit dose oral syringes. Based on prior studies assessing dosing strategies for sublingual administration utilizing a $1 \%$ ophthalmic solution of atropine $(15 \mathrm{ml})$, we determined that $1 \mathrm{mg} / 0.1 \mathrm{ml}$ would be an appropriate unit dose for administration. ${ }^{[2,4,6,8,10]}$ Ophthalmic atropine 1 $\mathrm{mg} / 0.1 \mathrm{ml}$ was drawn into one milliliter syringes, and could 
be administered four times daily as needed (four separate syringes). Per United States Pharmacopeia (USP) rules regarding packaging and repackaging single unit containers, once opened, atropine would have an expiration date of 30 days stored at room temperature. ${ }^{[11]}$

In addition to therapeutic benefits, there may be financial incentives to utilizing sublingual atropine versus systemic agents for secretion control. To date, there are no randomized trials assessing the efficacy of one agent over the other in gen- eral patient populations with excessive secretion production Atropine is only available commercially as either intravenous vial or ophthalmic solution. The average wholesaler price (AWP) of one five milliliter bottle of atropine ophthalmic solution costs $\$ 15.41$, whereas an injectable single-use vial costs $\$ 4.37$. As one five milliliter bottle can provide 50 doses, the cost for preparation of a single dose of sublingual atropine would be approximately $\$ 0.31 .^{[12]}$ Table 2 highlights the key cost differences of the anti-secretory agents described previously.

Table 2. Cost evaluation of anti-secretory agents

\begin{tabular}{|c|c|c|c|c|}
\hline Medication & Dose for Secretion Control* & Availability & $\operatorname{AWP}(\$)^{* *}$ & $\begin{array}{l}\text { Maximum Potential } 24 \\
\text { Hour Cost of Therapy }\end{array}$ \\
\hline \multirow{2}{*}{ Atropine } & \multirow{2}{*}{$\begin{array}{l}\text { One to two drops sublingually every } 6 \\
\text { hours as needed }\end{array}$} & $1 \% 5 \mathrm{ml}$ ophthalmic solution & 15.41 & 2.47 \\
\hline & & $0.4 \mathrm{mg} / \mathrm{ml}(1 \mathrm{ml})$ vial & 4.37 & 235.98 \\
\hline \multirow{3}{*}{ Glycopyrrolate } & \multirow{2}{*}{$\begin{array}{l}\text { One to two mg orally every six hours as } \\
\text { needed }\end{array}$} & One mg tablets & 1.31 & 9.36 \\
\hline & & Two mg tablets & 2.34 & 9.36 \\
\hline & $0.2 \mathrm{mg}$ IV every six hours as needed & $0.2 \mathrm{mg} / \mathrm{ml}$ injection & 18.00 & 72.00 \\
\hline \multirow{2}{*}{ Hyoscyamine } & \multirow{2}{*}{$\begin{array}{l}0.125 \mathrm{mg} \text { sublingual every four hours as } \\
\text { needed }\end{array}$} & $0.125 \mathrm{mg}$ tablets & 1.14 & 6.84 \\
\hline & & $0.5 \mathrm{mg} / \mathrm{ml}$ injection & 61.00 & 366.00 \\
\hline Scopolamine & $1.5 \mathrm{mg}$ transdermal patch every 72 hours & $1.5 \mathrm{mg}$ transdermal patch & 23.41 & 7.80 \\
\hline
\end{tabular}

*Lexicomp Online ${ }^{\circledR}$, Hudson, Ohio: Lexi-Comp, Inc.; May 21, 2015;

**AWP accessed from Redbook ${ }^{\circledR}$ and prices current as of 05/19/2015.

\section{Conclusions}

Although clinical trials are lacking, sublingual atropine is a potential option for symptom control in patients presenting with excessive respiratory secretions. Sublingual administration may limit systemic exposure minimizing adverse drug reactions. The administration of a medication via a different route of administration than intended has the potential for medication errors, as demonstrated from this patient case. There is a need for randomized controlled trials to examine the use of sublingual atropine for more generalized popula- tions. Institutions who use sublingual atropine may utilize the administration strategy described above to minimize accidental exposures as well as reduce potential costs of therapy. Based on our experiences with this patient and the use of sublingual atropine for secretion control, we recommend that the medication be administered via a syringe repackaged in the pharmacy to limit administration and labeling errors.

\section{CONFLICTS OF INTEREST Disclosure}

The authors have declared no conflicts of interest.

\section{REFERENCES}

[1] Pedersen C, Rosendahl-Nielsen M, Hjermind J, et al. Endotracheal suctioning of the adult intubated patient-what is the evidence? Intensive Crit Care Nurs. 2009; 25: 21-30. PMid:18632271 http: //dx.doi.org/10.1016/j.iccn.2008.05.004

[2] Protus B, Grauer P, Kimbrel J. Evaluation of atropine 1\% ophthalmic solution administered sublingually for the management of terminal respiratory secretions. Am J Hosp Palliat Care. 2013; 30(4): 38892. PMid:22833553 http://dx.doi.org/10.1177/104990911 2453641

Published by Sciedu Press
[3] Campbell B, Boustani M, Limbil T, et al. The cognitive impact of anticholinergics: a clinical review. Clin Interv Aging. 2009; 4: 225-33. PMid:19554093

[4] Brunton L, Chamber B, Knollman B, et al. Goodman \& Gilman's the pharmacological basis of therapeutics. 12th ed. New York: McGrawHill. 2011: 93-198.

[5] Mustafa FA, Khan A, Burke J, et al. Sublingual atropine for the treatment of severe and hyoscine-resistant clozapine-induced sialorrhea Afr J Psychiatry. 2013; 16: 236-42. http://dx.doi.org/10.43 14/ajpsy.v16i4. 32 
[6] Rapaport A. Sublingual atropine drops for the treatment of pediatric sialorrhea. J Pain Symptom Manage. 2010; 40(5): 783 8. PMid:20541902 http://dx.doi.org/10.1016/j.jpainsy mman.2010.02.007

[7] Atropine [monograph]. In: Lexicomp Online [online database]. Hudson, OH: Lexi-Comp (accessed 2015 May 15).

[8] De Simone GG, Eisenchlas JH, Junin M, et al. Atropine drops for drooling: a randomized controlled trial. Palliat Med. 2006; 20: 66571. PMid:17060265 http://dx.doi.org/10.1177/026921630 6071702
[9] Isopto (atropine) ophthalmic solution package insert. Fortworth, TX: Alcon Laboratories. 1995 Nov. PMid:12465075 http://dx.doi.o $\mathrm{rg} / 10.1002 / \mathrm{mds} .10276$

[10] Hyson CM, Johnson AM, Jog MS. Sublingual atropine for sialorrhea secondary to parkinsonism: a pilot study. Movement Disorders. 2002; 17(6): 1318-20.

[11] Hunt DG. USP Chapter 1136 Packaging and repackaging single unit containers. Pharmacopeial Forum. 2014; 30(5): 1722-1726.

[12] Redbook Online [online database]. Greenwood Village, CO: Truven Health Analytics. (accessed 2015 May 19). 